\title{
PERIPHERAL BLOOD IMMUNOLOGICAL FEATURES ASSOCIATED WITH AORTIC VALVE DISEASE AND ASCENDING THORACIC AORTA ANEURYSM AND DILATION
}

Kaushal Kishore Tiwari ${ }^{1}$, Silverio Sbrana ${ }^{2}$, Stefano Bevilacqua ${ }^{1}$, Paola Giungato ${ }^{3}$, Angela Pucci ${ }^{4}$, Filippo Santarelli ${ }^{1}$, Marco Solinas ${ }^{1}$, Mattia Glauber

\begin{abstract}
INTRODUCTION: Ascending thoracic aortic aneurysm (TAA) is a multi-factorial process in which histological modifications and immune-mediated inflammation are closely associated. The predominant role of a Th1-mediated response in influencing aortic wall remodeling, dilation, and aneurysm formation has been suggested by previous studies. Recently, the importance of chemokine receptors for Thl cells recruitment into vascular inflammatory sites, as well as of the balance between pro- and anti-inflammatory T-cell subsets in influencing the severity of coronary artery disease, have been described.
\end{abstract}

MATERALAND MATHODS: We evaluated activation markers and chemokine receptors expression on peripheral T-cell and NK cell subsets of subject with aortic valve disease associated with ascending TAA (ascending aortic diameter $>4 \mathrm{~cm}$ ) and undergoing elective surgery for TAA (Group A), in comparison with patients with aortic valve disease without TAA (ascending aortic diameter $<4 \mathrm{~cm}$ ) (Group B). Peripheral blood samples from the two groups were also compared for intracellular T-lymphocyte cytokine production, frequency of regulatory T cells (Treg) and soluble levels of cytokine and chemokines. The aortic size index (ASI) was considered a parameter able to reflect aortic pathophysiological modifications leading to aortic dilation.

RESULTS: The results demonstrated correlations between ASI values and CCR5 expression on CD3+, CD3+/CD8+, CD4+ and CD4+/CD28- T-cell subsets. In Group A the expression of CCR5 was higher on CD3+/CD8+, CD4+ and CD4+/CD28- T-cell subsets, when compared with Group B. CD4+ and CD4+/CD28- T-cells in Group A showed also a higher expression for the co-stimulatory molecule $\mathrm{CD} 28$ and the activation marker $\mathrm{CD} 25$, respectively. An increased expression of CXCR3 was found on $\mathrm{CD} 4+, \mathrm{CD} 3+/ \mathrm{CD} 8+$ and CD3+/TCR+ T-cell subsets in Group A. A higher circulating fraction of NK cells, together with a higher NK cell positivity for CX3CR1, were observed in aneurysmatic patients. Intracellular cytokine analysis demonstrated a higher fraction of CD3+/CD4+ T-cells producing IL-17A and IL-10 in Group A, together with a higher intracellular content for IL-21. Finally, a higher soluble level of fractalkine (CX3CL1) has been detected in aneurysm group.

CONCLUSION: Results indicate a higher activation state, migratory capacity and cytotoxic potential of peripheral blood $\mathrm{NK}$ and T-cell subsets in patients with aortic valve disease associated with ascending TAA, when compared with patients affected by aortic valve disease alone. These findings, together with the observed higher polarization towards a Th17 in patients with aortic aneurysm could suggest the involvement of autoimmune mechanisms leading to cellular loss, inflammation and fibrosis during ascending aortic wall dilation and aneurysmatic progression.

KEYWORDS: Thoracic aortic aneurysm; Aortic valve disease; Immune system; Inflammation; Flow cytometry

1. Department of Adult Cardiac Surgery, "G. Pasquinucci” Heart Hospital, Fondazione Toscana "G. Monasterio"

2. Flow Cytometry Laboratory, CNR Institute of Clinical Physiology, Pisa, Italy

3. Cellular Biology Laboratory, CNR Institute of Biomedical Technologies, Pisa, Italy

4. Department of Pathology, University of Pisa, Pisa, Italy

\author{
For Correspondence \\ Dr. Kaushal Kishore Tiwari PhD, MD \\ Department of Adult Cardiac Surgery \\ "G.Pasquinucci" Heart Hospital \\ Fondazione Toscana "G.Monasterio" \\ Via Aurelia Sud \\ 54100 Massa Italy \\ E-mail:drkaushalkt@yahoo.com
}




\section{INTRODUCTION}

Ascending thoracic aortic aneurysm (TAA) formation and progression is a multi-factorial process that involves both cellular and extracellular mechanisms. ${ }^{1.4}$ Several aspects of pathogenesis of the ascending aortic aneurysm formation and progression remain still unknown. In particular, the variable association of aortic aneurysm enlargement, dissection or rupture with primary aortic valve disease and perturbed blood flow, as well as with genetic individual characteristics, suggests the importance of an integrated evaluation including also cellular inflammatory mechanisms that could play a role in aortic wall structure damaging and dampening of its biomechanical properties. ${ }^{5-7}$

The aortic size index (ASI), calculated as ratio between the absolute aortic diameter and the body surface area, has been proposed as a parameter able to reflect aortic pathophysiological modifications and stratify the risk of aortic dissection or rupture. ${ }^{8}$

The role of a predominant Th1 immune-mediated response in controlling outward vascular remodeling and intimal expansion of ascending thoracic aortic aneurysm has been suggested by previous histological, immunohistochemical and molecular aortic tissue studies. ${ }^{9}$ A close association between the extent of aortic vascular remodeling and the local density of T-cell infiltration, chemokine receptors expression, and chemokines production clearly comes out from these studies. Moreover, because the importance of modified extracellular or secreted proteins as a source of autoantigens in the pathogenesis of autoimmune diseases. ${ }^{10}$

So far, no studies related peripheral blood T-cell phenotype and function with thoracic aortic aneurysm progression. In our study, we evaluated the presence of potential relationships between chemokine receptors and activation markers expression on circulating CD4+, CD8+, TCR + T-cell subsets and NK cells and the pathophysiological aortic modifications (in terms of ASI) in patients with aortic valve disease associated with different degrees of thoracic aortic dilation. We performed also the quantification (as percentage) and phenotypic characterization of the cytotoxic $\mathrm{CD} 4+/ \mathrm{CD} 28-\mathrm{T}$ cell subset known to react against stressed cells and involved in vascular damage ${ }^{11-12}$, as well as the measurement of the circulating fraction of the invariant NKT cell subset (iNKT) $\mathrm{CD} 3+/ \mathrm{V} 24+/ \mathrm{V} 11+$ producing profibrotic cytokines during chronic tissue inflammatory reactions. ${ }^{13}$ Moreover, we evaluated the functional polarization of circulating T-cell subsets by quantifying the intracellular production of proinflammatory (IFN-, IL-17A, IL-21) and anti-inflammatory
(IL-10) cytokines, with particular focusing towards the Th17 functional phenotype, known to be involved in several types of autoimmune inflammation and cardiovascular diseases. ${ }^{14-15}$ Since the importance of Th17/Treg balance in controlling vascular inflammation ${ }^{16-17}$, we quantified also the circulating fraction of the CD4+/CD25+/FoxP3+ regulatory T-cell subset (Treg). Finally, we quantified circulating levels of cytokines (IFN-, IL-6, IL-10, IL-17A, IL-23, TGF-) and chemokines (RANTES, CX3CL1) involved in T-lymphocyte functional polarization and migration into inflammatory sites.

\section{MATERIALAND METHODS}

\subsection{Patients and blood samples}

We studied 10 patients (mean age 65 years, range 59-71 years, male/female ratio of $8 / 2$ ) with aortic valve disease associated with ascending TAA (ascending aortic diameter $>4 \mathrm{~cm}$ ) and undergoing elective surgery for TAA (Group A), and 10 patients (Group B) matched for age and sex with Group A and undergoing aortic valve replacement for aortic stenosis or aortic regurgitation without TAA (ascending aortic diameter $<$ $4 \mathrm{~cm}$ ). Differences for cardiovascular risk factors like hypertension, smoking and diabetes were not significant between the two groups.

Aortic size index was calculated for all patients using the formula ascending aortic maximum diameter/body surface area as previously proposed ${ }^{8}$. All patients were under clinical observation at "Ospedale del Cuore"-Fondazione "G. Monasterio" - Massa (Italy). Exclusion criteria were the presence of genetic disorders associated to specific aortic wall modifications, autoimmune and chronic inflammatory diseases, active cancer or immunoproliferative diseases, re-do open heart procedures, contraindications for magnetic resonance investigation. The study protocol was approved by the local Ethical Committee, and informed consent was obtained from each subject before enrollment. Preoperatively, venous peripheral blood samples were collected in Vacutainer tubes (Becton Dickinson, Franklin Lakes, NJ, USA) containing $15 \%$ ethylenediamine-tetra-acetic acid $\left(\mathrm{K}_{3}\right.$-EDTA) solution or sodium-heparin (143 IU) as the anticoagulant.

Plasma samples were derived from $\mathrm{K}_{3}$-EDTA anti-coagulated blood centrifuged at $3,000 \mathrm{~g}$ for $10 \mathrm{~min}$ at $4^{\circ} \mathrm{C}$ and immediately frozen at $-80^{\circ} \mathrm{C}$.

\subsection{Data Acquisition and Analysis}

Blood cell count (number of cells per microliter) was carried out by using a routine cell analyzer. Flow cytometry was performed with a FACS scan instrument and Cell Quest software (Becton Dickinson, San Jose, CA, USA). Overtime 
monitoring of instrument alignment was carried out with CaliBRITE beads (Becton Dickinson). Flow data analysis of lymphocyte surface markers expression as well as of intracellular cytokines content was based on measurement of positive events (percentage) or on their relative fluorescence intensity (RFI), as previously described. ${ }^{18}$ ELISA tests were performed using the ASYS HITECH Gmbh Jupiter Microplate Reader (Eugendorf, Austria).

\subsection{Sample Preparation for Flow Cytometric Analysis}

2.3.1 Surface staining of T-lymphocyte subsets: Blood samples were stained according to a whole blood technique as previously reported $^{19-20}$. In brief, $\mathrm{K}_{3}$-EDTA anticoagulated blood samples were treated with an ammonium-chloride red cell lysing solution to isolate WBCs, washed twice with a phosphate buffered saline solution (PBS) containing bovine serum albumin 0.5\% (BSA) (Sigma Chemical Co., St. Louis, USA) and stained with appropriate volumes of the following combinations of Phycoerythrin (PE)-Cyanine 5 (Cy5) (PC5)-, Fluorescein Isothiocyanate (FITC)- and Phycoerythrin (PE)conjugated mouse anti-human monoclonal antibodies: CD4/CD28/CD25; CD4/CD28/CCR5; CD4/CD28/CXCR3; CD4/CD28/CX3CR1; CD3/CD8/CD25; CD3/CD8/CCR5/; CD3/CD8/CXCR3; CD3/CD8/CX3CR1; CD3/TCR/CD25; CD3/TCR/CCR5; CD3/TCR/CXCR3; CD3/TCR/CX3CR1; $\mathrm{CD} 3 / \mathrm{V} 24 / \mathrm{V} 11$.

Appropriate mouse isotype controls were carried out in parallel. Monoclonal antibodies were obtained from Becton Dickinson, Pharmingen (San Diego, CA, USA), Immunotech (Beckman Coulter, Fullerton, CA, USA), R\&D Systems (Abingdon, UK) and MBL International Corporation (Watertown, MA, USA).

The acquisition process was stopped after 30,000 lymphocytes, gated either morphologically (bivariate plot of forwards vs. side scatter) or on the basis of their CD4 or CD3 bright fluorescence expression (FL3), were collected for each sample (Figure 1).

\section{FIGURES AND FIGURE'S LEGENDS}

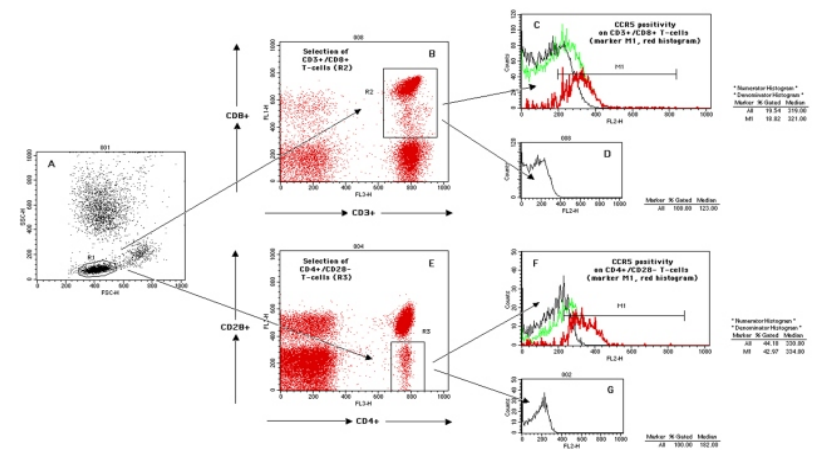

Figure 1: Representative example of T-lymphocyte subsets surface staining and analysis. A: Identification of lymphocytes (R1) initially based on their forward and side light scatter (SSC) properties. B and C: Dual parameter dot plot of FL1 versus FL3 showing representative examples of CD8 and $\mathrm{CD} 28$ staining on $\mathrm{CD} 3+$ and $\mathrm{CD} 4+$ bright populations, respectively. CD3+/CD8+ and CD4+/CD28- Tcell subsets are selected in R2 and R3 respectively. The overlaid histograms subtractions (test histogram control histogram) (D, E) are used to quantify the percentages of positivity for CCR5 (events in M1, filled histogram) and their RFI (linear scale) on the above selected T-cell subsets with respect to the corresponding isotype controls (dotted histograms).

2.3.2 Surface staining of NK cells: The circulating fraction of $\mathrm{NK}$ cells was quantified as CD3-/CD16+/CD56+ lymphocytes. The phenotype characterization of NK cells was based on the CD3-/CD56+ association as previously reported $^{21}$, by using the following monoclonal antibodies combinations: CD3/CD56/CD25; CD3/CD56/CCR5; CD3CD56/CXCR3; CD3/CD56/CX3CR1. Appropriate isotype controls were carried out in parallel. The acquisition process was stopped after 30,000 lymphocytes, gated either morphologically or on the basis of the CD3 bright fluorescence expression (FL3), were collected for each sample (Figure 2).

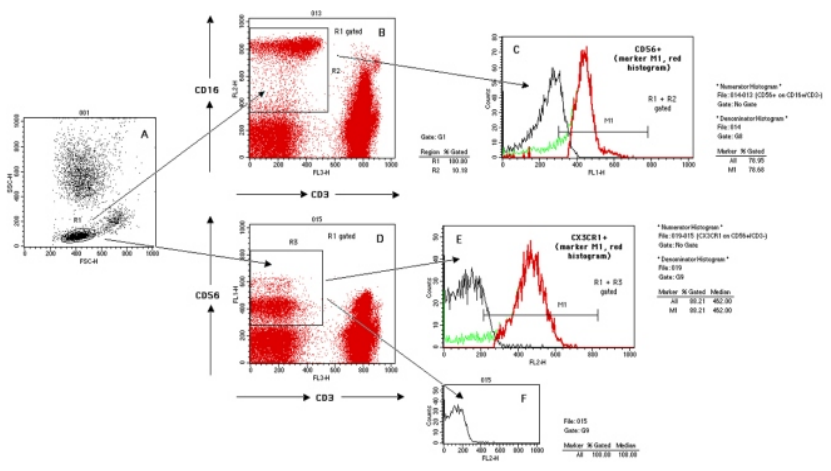

Figure 2: Representative example of flow cytometry quantification of NK cell lymphocyte's fraction and NK surface markers expression. A: Lymphocyte morphological selection initially based on a morphological scatter plot (R1). The CD3-/CD16+high subset is selected and quantified (percentage) in Panel $\mathrm{B}$, region $\mathrm{R} 2$. The derived overlaid histograms subtraction in Panel C (test histogram control histogram) is used to quantify the percentage of positivity for CD56 (events in M1, filled histogram). By multiplying these two percentages and dividing them by 100 , the lymphocyte's NK cell fraction is calculated. In panel D the CD3-/CD56+ NK cell population is selected (R3) and the derived overlaid 
histograms subtraction in panel $\mathrm{E}$ is used to quantify the percentage of positivity and RFI (linear scale) (events in M1, filled histogram) of $\mathrm{CX} 3 \mathrm{CR} 1$ with respect to the corresponding isotype control (dotted histograms).

2.3.4 Whole blood intracellular cytokine detection: The whole blood staining procedure of intracellular cytokines was based on previously described general protocols. ${ }^{22-23}$ In brief, heparinized whole blood samples were diluted 1:1 volume to volume with RPMI complete culture medium and incubated at density of $2 \times 10^{6} \mathrm{WBC} / \mathrm{ml}$ for 5 hours at $37^{\circ} \mathrm{C}$ in 24 wells plate. Phorbol Myristate Acetate (PMA) (Sigma Chemical Co.) with final concentration $50 \mathrm{ng} / \mathrm{ml}$ and Ionomycin (Sigma Chemical Co.) with final concentration $1 \mathrm{~g} / \mathrm{ml}$ were used as cellular activators in the presence of Brefeldin A (eBioscience Inc., San Diego, USA) with final concentration $3 \mathrm{~g} / \mathrm{ml}$ to trap produced cytokines into lymphocytes. At the end, diluted blood samples were recovered and treated with ammonium chloride red cell lysing solution to isolate WBCs.

Isolated cells were washed twice with a phosphate buffered saline solution containing bovine serum albumin $(0.5 \%)$ and stained on ice with appropriate volumes of the following combinations of PC5- and FITC-conjugated mouse antihuman monoclonal antibodies: CD3/CD4; CD3/CD8; CD3/TCR. Later on, isolated WBCs were washed with cold PBS, fixed on ice for 15 min with $2 \%$ formaldehyde fixation buffer and permeabilized at room temperature (RT) for $20 \mathrm{~min}$ with a saponin solution (0.5\%) (Sigma Chemical Co.). Cytokine staining was accomplished by incubation for $30 \mathrm{~min}$ at RT with appropriate volume of PE-labeled monoclonal antibodies directed against the following cytokines: IL-17A (eBioscience Inc.), IL-21 (eBioscience Inc.), IFN- (R\&D Systems) and IL-10 (R\&D Systems). Appropriate isotype controls were carried out in parallel either for surface or intracellular staining. Flow data acquisition was stopped after at least 30,000 lymphocytes, gated by a combination of morphological scatter plot and CD3 bright fluorescence expression (FL3), were collected for each sample (Figure 3).
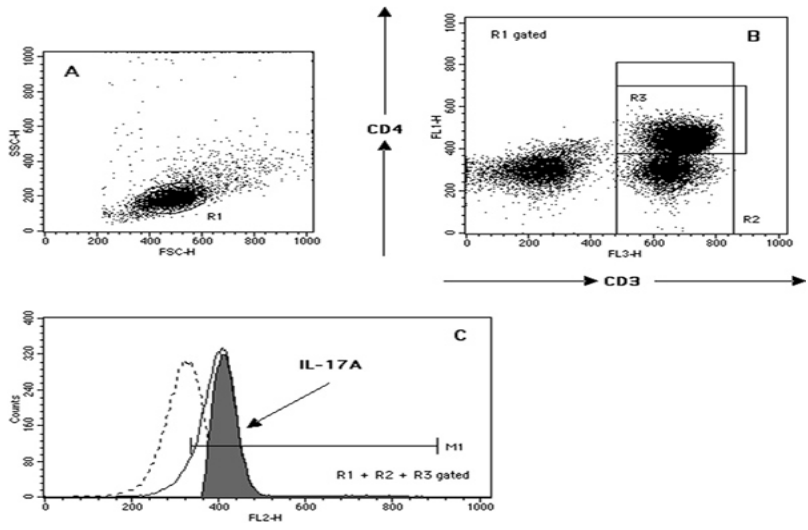

Figure 3: Representative example of flow cytometry quantification of T-lymphocyte subsets intracellular cytokine production in whole blood samples. CD4+ T-cell subset identification initially based on lymphocyte morphological light scatter properties (region R1, Panel A), then on the high reactivity for CD3 (FL3) (region R2, panel B) and CD4 (FL1) (region R3, Panel B). The derived overlaid histograms subtraction in Panel C (test histogram control histogram) is used to quantify the percentage of cells producing IL-17A (events in M1, filled histogram) and their RFI (linear scale) with respect to the corresponding isotype control (dotted histograms).

2.3.5 Regulatory T-cells (Tregs) identification : The staining procedure was based on validated protocols previously reported $^{16,24}$ with minor modifications. In brief, $\mathrm{K}_{3}$-EDTA anticoagulated blood samples were lysed as described above and the isolated WBCs were stained on ice for 30 min with appropriate volumes of PC5- and PE-conjugated mouse antihuman monoclonal antibodies directed against the surface markers CD4 (Immunotech) and CD25 (Pharmingen) respectively. Later on, cells were washed, fixed and permeabilized as described above, and stained for $30 \mathrm{~min}$ at RT with appropriate amount of Alexa Fluor 488-conjugated mouse anti-human forkhead box P3 (FoxP3) monoclonal antibody (eBioscience Inc.). Appropriate isotype controls were carried out in parallel either for surface or intracellular staining. Flow data acquisition was stopped after at least 30,000 lymphocytes, gated by a combination of morphological scatter plot and CD4 bright fluorescence expression (FL3), were collected for each sample (Figure 4).

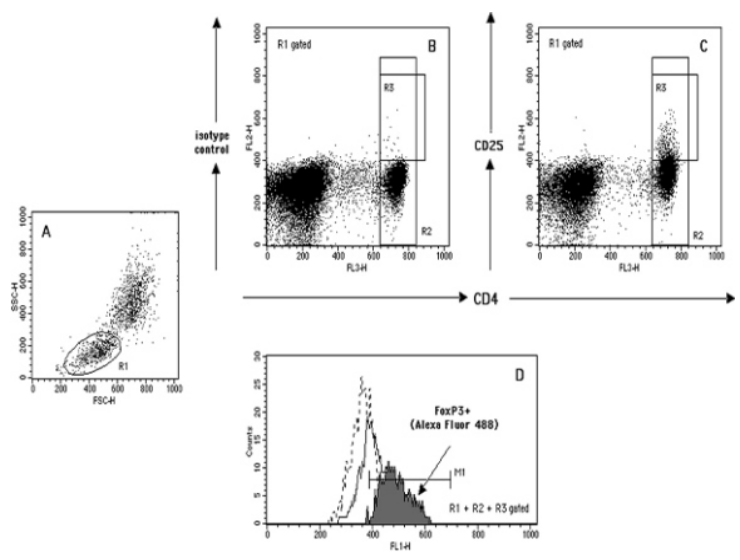

Figure 4: Representative example of flow cytometry quantification of circulating Treg frequency (FoxP3+ cells). The CD4+/CD25+ T-cell subset identification is initially based on lymphocyte morphological light scatter properties (region R1, Panel A), then on the high reactivity for CD4 
(FL3) (region R2, panels B and C). The selection of CD25+ cells (FL2) (region R3, panel C) is based on the corresponding isotype control level (region R3, panel B). The derived overlaid histograms subtraction in Panel D (test histogram control histogram) is used to quantify the percentage of FoxP3 + cells (events in M1, filled histogram) with respect to the corresponding isotype control (dotted histograms).

\subsection{ELISATests}

The presence in plasma samples of IFN-, IL-6, IL-10, IL-17A, IL-23, TGF-, RANTES, and CX3CL1 was detected and quantified by ELISA kits (R\&D Systems) according to the manufacturer's protocol. The minimum detectable concentrations for each cytokine were $15.6 \mathrm{pg} / \mathrm{ml}$ for IFN-, $0.156 \mathrm{pg} / \mathrm{ml}$ for IL- $6,0.78 \mathrm{pg} / \mathrm{ml}$ for IL- $10,31.25 \mathrm{pg} / \mathrm{ml}$ for IL$17 \mathrm{~A}, 39.0 \mathrm{pg} / \mathrm{ml}$ for IL-23, $31.2 \mathrm{pg} / \mathrm{ml}$ for TGF-, $31.2 \mathrm{pg} / \mathrm{ml}$ for RANTES, and $0.156 \mathrm{ng} / \mathrm{ml}$ for CX3CL1.

\subsection{Statistical Analysis}

Mean values of measurements and their standard errors of the mean (mean SEM) and linear regressions were calculated with StatView 5.0 software program (SAS Institute, Cary, NC, USA). The potential existence of statistically significant differences between groups was explored with t-test for unpaired data. $\mathrm{P}<0.05$ was considered statistically significant.

\section{RESULTS}

Ascending aortic diameter was significantly higher in Group A patients (48.6 $4.11 \mathrm{~mm}$ vs. $35.65 .4 \mathrm{~mm}, \mathrm{P}<0.001)$ and ASI was significantly higher in Group A in comparison to Group B (24.359 0.792 vs. $20.0080 .855 \mathrm{~mm}, \mathrm{P}=0.0015)$.

Differences for total lymphocytes number ( $\mathrm{n}^{\circ}$ of cell/1), as well as for circulating fractions (percentages) of total $\mathrm{CD} 3+$, CD4+, CD4+/CD28-, CD3+/CD8+ and CD3+/TCR+ T-cell subsets were not significant between the two groups. Interestingly, an evident increment of the iNKT fraction, although statistically not significant, has been observed in the aneurysm group $(0.2300 .130$ vs. $0.0510 .014, \mathrm{P}=\mathrm{ns})$.

Taking into consideration that ASI predicts the risk of rupture or dissection of the aorta, we have initially performed a cumulative correlation (including all patients) between this index and the different phenotypic and functional lymphocyte aspects. Particularly, a significant positive correlations have been found between individual ASI values and CCR5 expression (percentage of positivity) on total $\mathrm{CD} 3+$, $\mathrm{CD} 3+/ \mathrm{CD} 8+$ and CD4+/CD28- T-cells subsets (Figure 5).
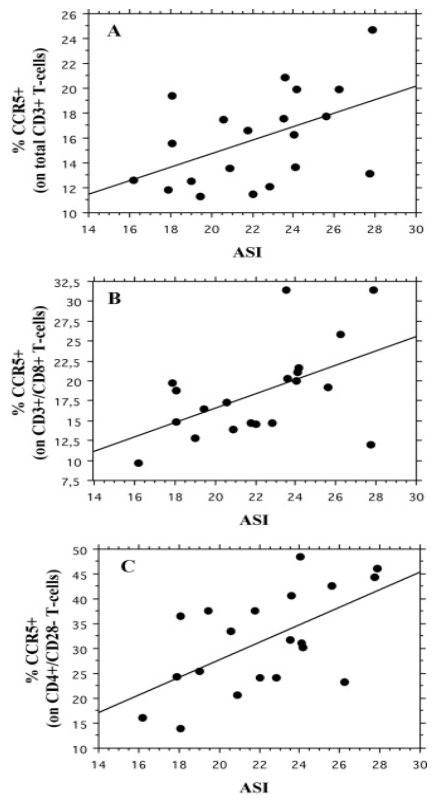

Figure 5: Linear correlations between individual ASI values (all patients) and the corresponding percentages of positivity for CCR5 on total $\mathrm{CD} 3+\left(\mathrm{A}, \mathrm{R}^{2}=0.238, \mathrm{P}=0.0293\right)$, $\mathrm{CD} 3+/ \mathrm{CD} 8+\left(\mathrm{B}, \mathrm{R}^{2}=0.272, \mathrm{P}=0.0183\right)$ and $\mathrm{CD} 4+/ \mathrm{CD} 28-(\mathrm{C}$, $\left.\mathrm{R}^{2}=0.355, \mathrm{P}=0.0055\right)$ peripheral blood T-cell subsets. An evident cumulative positive correlation, even if statistically not significant $\left(\mathrm{R}^{2}=0.147, \mathrm{P}=0.0949\right)$, has been also observed between individual ASI values and CCR5 expression on CD4+ T-cells. In addition to its positive correlation with ASI, when the CCR5 expression on CD3+/CD8+, CD4+/CD28- and CD4+ T-cell subsets was separately evaluated in Group A and Group B patients, an increased percentage of positivity has been observed in the aneurysm group (Table 1).

Table 1: CCR5 surface expression (percentage of positivity) on peripheral blood $\mathrm{CD3}+/ \mathrm{CD} 8+, \mathrm{CD} 4+/ \mathrm{CD28}$ and CD4+ T-cell subsets in Group A and Group B patients

\begin{tabular}{|c|c|c|c|}
\hline & Group A & Group B & $P$ value \\
\hline CD3+/CD8+ & $20.892 \pm 2.159$ & $16.119 \pm 1.126$ & 0.0656 \\
\hline CD4+/CD28- & $34.472 \pm 2.533$ & $28.807 \pm 3.594$ & ns \\
\hline CD4+ & $16.087 \pm 1.089$ & $13.115 \pm 0.816$ & 0.0424 \\
\hline
\end{tabular}

Moreover, when focused on CD4+ T-cells, the statistical analysis revealed an increased RFI expression for CXCR3 (linear scale) in Group A in comparison to Group B (290.250 11.551 vs. $252.60010 .837, \mathrm{P}=0.0287)$. An increased RFI expression for CXCR3 in Group A has been also detected on CD3+/TCR+ T-cells, although statistically not significant (270.500 16.509 vs. $233.80017 .271, \mathrm{P}=\mathrm{ns})$. 
In aneurysm group we have also observed an increased circulating fraction of $\mathrm{NK}$ cells (CD3-/CD16+/CD56+) mainly dependent on an up-regulated expression of CD56, as shown in Table 2.

Table 2: NK cell fraction (of total lymphocytes) and CD56 surface expression in Group A and Group B patients

\begin{tabular}{|c|c|c|c}
\hline & Group A & Group B & $P$ value \\
\hline NK cell fraction & $10.623 \pm 1.366$ & $8.042 \pm 1.217$ & ns \\
\hline $\begin{array}{c}\text { CD56 \% of positivity } \\
\text { (on CD3-/CD16+) }\end{array}$ & $76.432 \pm 2.518$ & $65.014 \pm 4.165$ & 0.0306 \\
\hline
\end{tabular}

Moreover, peripheral CD3-/CD56+ NK cells of Group A exhibited a potentially increased migratory capacity in response to fractalkine, as suggested by their higher positive fraction for fractalkine receptor CX3CR1, when compared with Group B (87.054 1.864 vs. 80.286 3.031, $\mathrm{P}=0.0733$ ).

The analysis of intracellular cytokines revealed an increased fraction of CD3+/CD4+ T-cells pruducing IL-17A and IL-10 in the aneurysm group, when compared with aortic valve group (Figure 6).

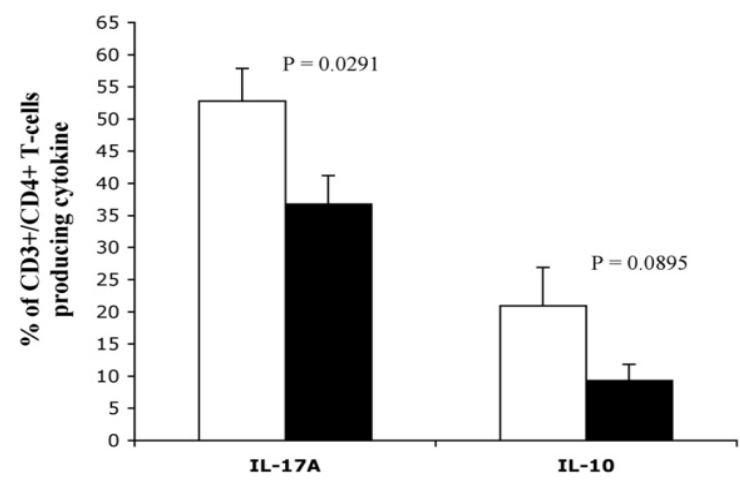

Figure 6: Comparative analysis of IL-17A and IL-10 intracellular cytokine production by circulating $\mathrm{CD} 3+/ \mathrm{CD} 4+$ T-lymphocytes in Group A (open bars) and Group B (solid bars) patients

The higher frequency of CD4+ T-cells producing IL-17A observed in our study, when compared with previous paper ${ }^{16}$, depends on the different algorithm employed for calculation of positive events. In fact, the overlaid histograms subtraction procedure, that we used, includes also dim positive events that are excluded using a dot plot quadrant statistics. ${ }^{16}$ The IL-17A and IL-10 intracellular production by CD3+/CD4+ T-cells was also characterized by an evident increase of these cytokine's amount per cell, expressed as RFI, in the Group A patients in comparison to aortic valve group (87.700 $4.849 \mathrm{vs}$. $72.1003 .335, \mathrm{P}=0.0163$ and $84.350 \quad 8.732$ vs. 64.100 $12.111, \mathrm{P}=\mathrm{ns}$, respectively), as well as by an evident increment of RFI for IL-21 production, although statistically not significant (152.000 5.968 vs. $138.200 \quad 5.953, \mathrm{P}=\mathrm{ns})$. Furthermore, an apparent augmentation of fraction of CD3+/CD8+ and CD3+/TCR+ T-cells producing IL-17A and IL-10 has been observed in peripheral blood of Group A patients (Table 3 and Table 4).

Table 3: Percentages of circulating CD3+/CD8+ T-cells producing IL-17A and IL-10 in Group A and Group B patients

\begin{tabular}{|c|c|c|c|}
\hline & Group A & Group B & $P$ value \\
\hline IL-17A & $47.189 \pm 5.535$ & $35.750 \pm 4.754$ & ns \\
\hline IL-10 & $13.578 \pm 4.116$ & $5.928 \pm 1.702$ & ns \\
\hline
\end{tabular}

Table 4: Percentages of circulating CD3+/TCR+ T-cells producing IL-17A and IL-10 in Group A and Group B patients

\begin{tabular}{|c|c|c|c|}
\hline & Group A & Group B & $P$ value \\
\hline IL-17A & $50.649 \pm 5.510$ & $36.893 \pm 3.463$ & 0.0488 \\
\hline IL-10 & $20.120 \pm 4.406$ & $11.570 \pm 1.957$ & 0.0931 \\
\hline
\end{tabular}

No difference in the circulating Treg (FoxP3+) fraction has been found between Group A and Group B patients, as shown in Table 5 .

Table 5: Circulating fraction (percentage) of FoxP3+ Tregs in Group A and Group B patients

\begin{tabular}{|c|c|c|c|}
\hline & Group A & Group B & $P$ value \\
\hline FoxP3 & $36.243 \pm 4.769$ & $35.327 \pm 5.542$ & $n s$ \\
\hline
\end{tabular}

Finally, quantification of soluble cytokines by ELISA tests discovered an increment in fractalkine (CX3CL1) level $(\mathrm{ng} / \mathrm{ml})$ in aneurysm group compared to aortic valve group patients $(0.5220 .027$ vs. $0.434 \quad 0.030, \mathrm{P}=0.0434)$. There were no significant differences in the level of other studied cytokines and chemokines (data not shown).

\section{DISCUSSION}

Previous studies, performed by histological and immuno histochemical procedures, demonstrated a Th1-mediated immunological involvement, mainly driven by the IFNproduction, in ascending thoracic aortic aneurysm (TAA) formation and evolution. ${ }^{9}$ In particular, the intensity of the Th1 immune-mediated inflammation shows a positive correlation with outward aortic wall remodeling and intimal 
expansion as well as with histopathological features like elastic fragmentation, cystic medial necrosis and medial fibrosis ${ }^{25}$.

So far, no study has been focused on evaluation of phenotype and functional state of circulating T-cell subsets in patients with ascending TAA. In our study, we applied flow cytometric and ELISA procedures to this assessment, in order to identify a possible role of phenotype and functional characteristics of the main blood T-cells subsets in the ascending TAA evolution. Moreover, we correlated immunological parameters with individual aortic size index (ASI) values, assuming that ASI is an important parameter able to reflect the extent of aortic wall damage and the risk of rupture.

We have identified a possible involvement of the chemokine receptor CCR 5 in the pathogenesis of aortic aneurysm, which is in agreement with previous studies demonstrating a role of this receptor in Th1 cell recruitment and activation during atherosclerosis and autoimmune vascular inflammation. ${ }^{26-27}$ The important role played by CCR5 in the ascending thoracic aortic dilation and TAA formation is suggested, in our study, by the positive correlations observed in all patients between individual ASI values and CCR5 surface expression on total $\mathrm{CD} 3+, \mathrm{CD} 3+/ \mathrm{CD} 8+, \mathrm{CD} 4+/ \mathrm{CD} 28-$ and CD4+ circulating Tcell subsets. The supposed pathophysiological association between CCR 5 expression level on peripheral T-lymphocytes, in particular on CD3+/CD8+, CD4+/CD28- and CD4+ T-cell subsets, and aortic wall damage, is further confirmed by the observed higher expression level of this chemokine receptor in Group A when compared with Group B patients. Furthermore, on the basis of a previous paper [28] demonstrating an increased CCR5 expression on bone marrow and peripheral blood activated CD4+ and CD8+ Tlymphocytes, we can suppose the presence of a higher activation state of these T-cell subsets in aneurysm group compared to aortic valve group patients. This hypothesis seems sustained by the higher fraction of circulating CD4+ Tlymphocytes expressing the activation marker and costimulatory molecule CD28 (96.873 0.969 vs. 92.622 2.103, $\mathrm{P}=0.0830$ ), as well as by the higher percentage of blood CD3+/CD8+ T-cells bearing the activation marker CD25 (10.052 2.830 vs. $7.0851 .373, \mathrm{P}=\mathrm{ns}$ ) in Group A when compared with Group B. Besides CCR5, other chemokine receptors revealed an increased cellular expression in aneurysm group, when compared with aortic valve patients. In particular, CXCR3 level was higher (in terms of RFI) on CD4+ and CD3+/TCR+ T-cell subsets. Interestingly, an increased positivity for CXCR3 (in terms of percentage) characterizes also the circulating cytotoxic T-cell subset CD3+/CD8+(67.573 2.643 vs. 62.152 1.308, $\mathrm{P}=0.0826)$.
The pathophysiological relevance of immune-mediated cytotoxic mechanisms in conditioning aortic wall damage, vessel dilation, and aneurysm progression, is also suggested by the higher number of circulating NK cells, their higher expression of fractalkine receptor CX3CR1 (in association with a higher level of circulating chemokine CX3CL1) and their higher positivity for the activation and target adhesion marker CD56 ${ }^{29}$ in Group A when compared with Group B. Moreover, the significant correlation between individual ASI values and CCR5 expression on circulating cytotoxic CD4+/CD28- T-cells, together with the higher activation state (percentage of positivity for CD25) of this cell subset in Group A when compared with Group B (13.800 1.177 vs. 8.561 $1.528, \mathrm{P}=0.0142$ ) provide further support to the hypothesis of involvement of cytotoxic mechanisms in aortic wall damage leading to aortic dilation and aneurysm.The cytometric analysis of intracellular cytokine production by peripheral blood T-cell subsets has not shown the IFN- functional polarization already demonstrated into aneurysmatic aortic wall by immunohistochemical procedures. ${ }^{9}$ In fact, we have observed a higher intracellular production, as percentage of positivity and RFI, of IL-17A and IL-10 by circulating CD3+/CD4+ T-cells, together with an evident increment of RFI for IL-21 in Group A when compared with Group B patients. These data, once explained at the light of the recent demonstration that Th17 cells comprise a functional spectrum ranging from the "classical" more regulated cell subset (producing higher levels of IL-17A in association with IL-21 and IL-10) to the "alternative" more pathogenic cell subset (producing lower levels of IL-17A, IL-10 and IL-21 in association with higher levels of IFN- and GM-CSF) ${ }^{30}$, could suggest the presence of a more evident polarization towards a Th17 "classical" functional phenotype in the peripheral blood of aneurysm group compared to aortic valve group patients. This argument seems supported also by the relationships between IL-17A and IL-21 production by CD3+/CD4+ Tcells, both in terms of percentage of positivity and RFI, in Group A, as well as by the evident positive correlation between circulating levels of TGF- and the intracellular content of IL-10 (as RFI) in the same group of patients (Fig. 7). Such a correlations were not evident in Group B (data not shown).
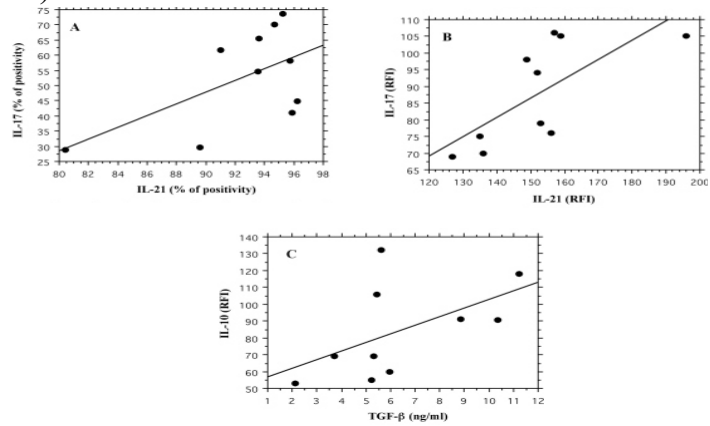
Figure 7: Relationships between IL-17A and IL-21 production by circulating $\mathrm{CD} 3+/ \mathrm{CD} 4+$ T-lymphocytes in Group A patients, in terms of percentage of positivity (panel A) and RFI (panel B); relationship between TGF- plasma levels and Tlymphocyte IL-10 content (as RFI) in the same group (panel C).

It has been shown that Th17 cells are functionally very plastic and that the "classical" more regulated Th17 subset has the possibility to switch towards IFN- producing cells ("alternative" Th17 subset) relatively easily in vivo in the presence of IL-23. . $^{31-32}$ We did not observe a significant difference of soluble IL-23 and IFN- cytokine levels in peripheral blood between Group A and Group B. However, the presence of evident relationships between soluble levels of IL23 and intracellular production of IL-17A $\left(\mathrm{R}^{2}=0.352, \mathrm{P}=\right.$ $0.0704)$ and IFN- $\left(\mathrm{R}^{2}=0.440, \mathrm{P}=0.0366\right)$ by $\mathrm{CD} 3+/ \mathrm{CD} 4+\mathrm{T}-$ cells (as percentage) in Group B, together with their absence in Group A (data not shown), seems to confirm the orientation towards a circulating Th17 more regulated functional phenotype in ascending TAA patients. Therefore, in order to achieve a better understanding of the IL-23/IL-17A immune pathway in influencing chronic inflammation during aortic dilation and ascending TAA formation, it could be useful to quantify IL-23 locally produced in aortic damaged tissues and correlate this parameter with tissue infiltration by Th17 cells producing IFN-.

Moreover, when compared with "alternative" subset, "classical" more regulated Th17 cells produce higher levels of pro-fibrotic cytokines such as IL-10 and IL-21..$^{33}$ Such action makes this cell subset a candidate effector in the process leading to cellular loss and medial fibrosis during ascending TAA development. ${ }^{25}$ The increased intracellular production of IL-17A and IL-10 by peripheral CD3+/CD8+ and $\mathrm{CD} 3+/ \mathrm{TCR}+\mathrm{T}$-cells, as well as the higher circulating fraction of the pro-fibrotic iNKT cell subset ${ }^{13}$, observed in Group A patients, might contribute to amplify the functional effects of "classical" Th17 cells once recruited into aneurysmatic aortic wall. As a consequence, the increased level of circulating fractalkine in Group A might reflect the presence of a higher endothelial activation induced by a more active cell-mediated inflammation into aneurysmatic aortic wall.

On the other hand, the lack of difference in the blood Treg cells (FoxP3+) frequency between Group A and Group B seems to exclude the presence of a systemic chronic autoimmune disease in aneurysmatic patients when compared with aortic valve patients. In fact, previous studies reported that the number of circulating CD4+/CD25+/FoxP3+Treg cells decreases in several types of systemic autoimmune diseases. ${ }^{34-}$ 35 However, the observed higher frequency of "classical"
Th17 cells in aneurysmatic patients, together with the recent demonstration that considerable numbers of human CD4+ Tcell are flexible and coexpress FoxP3 and RORt (the main master regulator of "classical" Th17 cells) ${ }^{36-37}$, could have determined an overestimation of the CD4+/CD25+/FoxP3+ Treg subset in Group A when compared with Group B. The use of surface markers specifically associated with human Th17 cell differentiation ${ }^{38}$, in particular the chemokine receptor CCR6, together with the functional capacity to produce IL17A upon activation, could be used to determine the circulating fraction of this flexible CD4+ T-cell subset and to obtain, indirectly, a more precise quantification of the fully committed immunosuppressive FoxP3+ Treg population. If further studies will be able to demonstrate a reduced level of CD4+/CD25+/FoxP3+ T-cells in ascending TAA patients when compared with aortic valve patients, the phenotype and functional data described in the present study might indicate the involvement of an autoimmune response in the pathogenesis of ascending TAA, as previously suggested for abdominal aortic aneurysm.

\section{SOURCES OF FUNDING}

This work was supported by the National Research Council (CNR) of Italy, RSTL (Curiosity Driven Research Program) DG.RSTL.035.006-035.

\section{REFERENCES}

1. Elefteriades JA. Thoracic aortic aneurysm: reading the enemy's playbook, Curr. Probl. Cardiol.2008;33:203-77. http://dx.doi.org/10.1016/j.cpcardiol.2008.01.004 PMid: 18439439

2. Lesauskaite V, Tanganelli P, Sassi C, Neri E, Diciolla F, Ivanoviene L et al. Smooth muscle cells of the media in the dilatative pathology of ascending thoracic aorta: morphology, immunoreactivity for osteopontin, matrix metalloproteinases, and their inhibitors, Hum. Pathol. 2001;32:1003-1111. http://dx.doi.org/10.1053/hupa.2001.27107 PMid:11567232

3. Iliopoulos DC, Kritharis EP, Giagini AT, Papadodima SA, Sokolis DP. Ascending thoracic aortic aneurysm are associated with compositional remodeling and vessel stiffening but not weakening in age matched subjects, J. Thorac. Cardiovasc. Surg. 2009;137:101-9.

http://dx.doi.org/10.1016/j.jtcvs.2008.07.023 PMid:19154911

4. Schmid FX, Bielenberg K, Schneider A, Haussler A, Keyser A, Birnbaum D. Ascending aortic aneurysm associated with bicuspid and tricuspid aortic valve: involvement and clinical relevance of smooth muscle cell apoptosis and expression of cell death-initiating proteins. Eur. J. Cardiothorac. Surg.2003; 23:537-43. 
5. Pearson GD, Devereux $R$, Loeys B, Maslen $C$, Milewicz D, Pyeritz R et al. Report of the National Heart, Lung, and Blood Institute and National Marfan Foundation Working Group on reseach in Marfan Syndrome and related disorders, Circulation.2008; 118:785-91.http://dx.doi.org /10.1161/ CIRCULATIONAHA.108.783753PMid:18695204 PMCid: PMC2909440

6. Pachulski RT, Weinberg AL, Chan KL. Aortic aneurysm in patients with functionally normal or minimally stenotic bicuspid aortic valve, Am. J. Cardiol. 1991;67:781-2.

http://dx.doi.org/10.1016/0002-9149(91)90544-U

7. Loscalzo ML, Goh DL, Loeys B, Kent KC, Spevak PJ, Dietz HC. Familial thoracic aortic dilation and bicommissural aortic valve: a prospective analysis of natural history and inheritance, Am. J. Med. Genet. A. 2007;143:1960-7. http ://dx.doi.org/ 10.1002/ajmg.a.31872 PMid:17676603

8. Davies RR, Gallo A, Coady MA, Tellides G, Botta DM, Burke B et al. Elefteriades, Novel measurement of relative aortic size predicts rupture of thoracic aortic aneurysm, Ann. Thorac. Surg. 2006;81:169-77. http://dx.doi.org/10.1016/j.athoracsur. 2005.06 .026

9. Tang PCY, Yakimov AO, Teesdale MA, Coady MA, Dardik A, Elefteriades JA et al. Transmural inflammation by interferon- $\gamma$ producing $T$ cells correlates with outward vascular remodeling and intimal expansion of ascending thoracic aortic aneurysm, FASEB J. 2005;19:1528-30. PMid:16014397

10. Haskins K, Cooke A. CD4 T cells and their antigens in the pathogenesis of autoimmune diabetes, Curr. Opin. Immunol. 2011; 23:739-45. http://dx.doi.org/10.1016/j.coi.2011.08.004 PMid:21917439 PMCid:PMC3940273

11. van de Berg PJ, van Leeuwen EM, ten Berge IJ, van Lier R. Cytotoxic human CD4+ T cells, Curr. Opin. Immunol.2008; 20:339-43. http://dx.doi.org/10.1016/j.coi.2008.03.007 PMid :18440213

12. Zal B, Kaski JC, Arno G, Akiyu JP, Xu Q, Cole D et al. Heatshock protein 60-reactive CD4+CD28null $T$ cells in patients with acute coronary syndromes, Circulation.2004;109:1230-5. http://dx.doi.org/10.1161/01.CIR.0000118476.29352.2A PMid:14993140

13. de Lalla C, Galli G, Aldrighetti L, Romeo R, Mariani M, Monno $A$ et al. Production of profibrotic cytokines by invariant NKT cells characterizes cirrhosis progression in chronic viral hepatitis, J. Immunol.2004;173: 1417-25. http: //dx.doi.org/ 10.4049/jimmunol.173.2.1417

14. Kikly K, Liu L, Na S, Sedgwick JD. The IL-23/Th17: therapeutic targets for autoimmune inflammation, Curr. Opin. Immunol. 2006;18:670-5. http://dx.doi.org/10.1016/j.coi.2006.09.008

\section{PMid:17010592}

15. Liuzzo G, Trotta F, Pedicino D. Interleukin-17 in atherosclerosis and cardiovascular disease: the good, the bad, and the unknown, Eur. Heart J. 2012 Nov 23 [Epub ahead of print] doi: 10.1093/eurheartj/ehs399. http://dx.doi.org/10.1093/eurheartj/ehs399

16. Cheng $X$, Yu $X$, Ding YJ, Fu QQ, Xie JJ, Tang TT et al. The Th17/Treg imbalance in patients with acute coronary syndrome, Clin. Immunol. 2008;127:89-97. http://dx.doi.org/10.1016/j.clim.2008.01.009 PMid:18294918

17. George J, Schwartzenberg S, Medvedovsky D, Jonas M, Charach G, Afek A et al. Regulatory T cells and IL-10 levels are reduced in patients with vulnerable coronary plaques, Atherosclerosis. 2012; 222:519-23. http://dx.doi.org/10.1016/j.atherosclerosis.2012.03.016 PMid:22575708

18. Sbrana S, Parri MS, De Filippis R, Gianetti J, Clerico A. Monitoring of monocyte functional state after extracorporeal circulation: a flow cytometry study, Cytometry Part B (Clinical Cytometry).2004;58B:17-24.

http://dx.doi.org/10.1002/cyto.b.10061 PMid:14994371

19. Stewart CC, Stewart SJ. Cell preparation for the identification of leukocytes. In: Darzynkiewicz Z, Crissman HA, Robinson JP, editors. Methods in cell biology. Volume 63. San Diego, CA: Academic Press; 2001:217-51.PMid:11060844

20. Sbrana S, Bevilacqua S, Buffa M, Spiller D, Parri MS, J. Gianetti, R. De Filippis, A. Clerico, Post-reperfusion changes of monocyte function in coronary blood after extracorporeal circulation, Cytometry Part B (Clinical Cytometry).2005; 65B:14-21.http://dx.doi.org/10.1002/cyto.b.20049 PMid: 15786508

21. Prado-Drayer A, Teppa J, Sànchez P, Camejo MI. Immunophenotype of peripheral $T$ lymphocytes, $N K$ cells and expression of CD69 activation marker in patients with recurrent spontaneous abortions, during the mid-luteal phase. Am. J. Reprod. Immunol.2008; 60:66-74.

http: //dx.doi.org/10.1111/j.1600-0897.2008.00591.x PMid:18593439

22. Maino VC, Picker LJ. Identification of functional subsets by flow cytometry: intracellular detection of cytokine expression, Cytometry (Communications in Clinical Cytometry). 1998;34:207-15. http://dx.doi.org/10.1002/(SICI)1097-0320(19981015)34:5< $207 \because A I D-C Y T O 1>3.0 . C O ; 2-J$

23. Nomura LE, Walker JM, Maecker HT. Optimization of whole blood antigen-specific cytokine assays for CD4+T cells, Cytometry. 2000; 40:60-8. http ://dx.doi.org/10.1002/(SICI)1097-0320 (20000501) 40:1< 


$$
60:: A I D-C Y T O 8>3.0 . C O ; 2-J
$$

24. Grant J, Bourcier K, Wallace S, Pan D, Conway A, SeyfertMargolis V et al. Validated protocol for FoxP3 reveals increased expression in type 1 diabetes patients, Cytometry Part $B$ (Clinical Cytometry) 76B (2009) 69-78.

http://dx.doi.org/10.1002/cyto.b.20446 PMid:18690669

25. Balistreri CR, Pisano C, Candore G, Maresi E, Codispoti $M$, Ruvolo G. Focus on the unique mechanisms involved in thoracic aortic aneurysm formation in bicuspid aortic valve vs tricuspid aortic valve patients: clinical implications of a pilot study. Eur. J. Cardiothorac. Surg. 2012 Dec 17 [Epub ahead of print] doi:10.1093/ejcts/ezs630.

http://dx.doi.org/10.1093/ejcts/ezs630

26. Zhao Q. Dual targeting of CCR2 and CCR5: therapeutic potential for immunological and cardiovascular diseases. $J$. Leukoc. Biol. 2010;88:41-55.

http: //dx.doi.org/10.1189/jlb.1009671 PMid:20360402

27. Crane IJ, Xu H, Wallace C, Manivannan A, Mack M, Liversidge J et al. Involvement of CCR5 in the passage of Th1-type cells across the blood-retina barrier in experimental autoimmune uveitis. J. Leukoc. Biol. 2006;79: 435-43.

http: //dx.doi.org/10.1189/jlb.0305130 PMid:16365158

28. Herndler-Brandstetter D, Landgraf K, Jenewein B, Tzankov A, Brunauer $R$, Brunner $S$ et al. Human bone marrow hosts polyfunctional memory CD4+ and CD8+T cells with close contact to IL-15-producing cells. J. Immunol. 2011; 186:696571.http://dx.doi.org/10.4049/jimmunol.1100243 PMid:21562158

29. Hurd T, Walker J, Whalen MM. Pentachlorophenol decreases tumor-cell-binding capacity and cell-surface protein expression of human natural killer cells. J. Appl. Toxicol. 2012;32:627-34. http://dx.doi.org/10.1002/jat.1781 PMid:22912977 PMCid:PMC3428751

30. Peters A, Lee Y, Kuchroo VK. The many faces of Th17 cells. Curr Opin Immunol. 2011 Dec;23(6):702-6. http://dx.doi.org/10.1016/j.coi.2011.08.007 PMid:21899997 PMCid:PMC3232281

31. Lee YK, Turner H, Maynard CL, Oliver JR, Chen D, Elson CO, Weaver CT. Late developmental plasticity in the Thelper 17 lineage. Immunity. 2009 Jan 16;30(1):92-107. http://dx.doi.org/10.1016/j.immuni.2008.11.005 PMid:19119024 PMCid:PMC3607320

32. Kikly K, Liu L, Na S, Sedgwick JD. he IL-23/Th(17) axis: therapeutic targets for autoimmune inflammation. Curr Opin Immunol. 2006 Dec;18(6):670-5.

http ://dx.doi.org/10.1016/j.coi.2006.09.008 PMid:17010592

33. Wick G, Backovic A, Rabensteiner E, Plank N, Schwentner C,
Sgonc R. The immunology of fibrosis: innate and adaptive responses. Trends Immunol. 2010 Mar;31(3):110-9. http://dx.doi.org/10.1016/j.it.2009.12.001

PMid:20106721 PMCid:PMC3292796

34. Crispin JC, Martinez A, Alcocer-Varela J. Quantification of regulatory T cells in patients with systemic lupus erythematosus. JAutoimmun. 2003 Nov;21(3):273-6.

http ://dx.doi.org/10.1016/S0896-8411(03)00121-5

35. Viglietta V, Baecher-Allan C, Weiner HL, Hafler DA. Loss of functional suppression by $C D 4+C D 25+$ regulatory $T$ cells in patients with multiple sclerosis. J Exp Med. 2004 Apr 5;199 (7):971-9.

http://dx.doi.org/10.1084/jem.20031579 PMid:15067033 PMCid:PMC2211881

36. Nakayamada S, Takahashi H, Kanno Y, O'Shea JJ. Helper T cell diversity and plasticity. Curr Opin Immunol. 2012 Jun;24(3):297-302. http://dx.doi.org/10.1016/j.coi.2012.01.014 PMid:22341735 PMCid:PMC3383341

37. Voo KS, Wang YH, Santori FR, Boggiano C, Wang YH, Arima K, et al. Identification of IL-17-producing FOXP3 + regulatory $T$ cells in humans. Proc Natl Acad Sci U S A. 2009 Mar 24;106(12):4793-8.

http://dx.doi.org/10.1073/pnas.0900408106 PMid:19273860 PMCid:PMC2653560

38. Annunziato F, Cosmi L, Liotta F, Maggi E, Romagnani S. Defining the human Thelper 17 cell phenotype. Trends Immunol. 2012 Oct;33(10):505-12.

http://dx.doi.org/10.1016/j.it.2012.05.004 PMid:22682163

39. Jagadesham VP, Scott DJ, Carding SR. Abdominal aortic aneurysms: an autoimmune disease? Trends Mol Med. 2008 Dec;14(12):522-9.

http://dx.doi.org/10.1016/j.molmed.2008.09.008 PMid:18980864

40. Yin M, Zhang J, Wang Y, Wang S, Böckler D, Duan Z, Xin S. Deficient $C D 4+C D 25+T$ regulatory cell function in patients with abdominal aortic aneurysms. Arterioscler Thromb Vasc Biol. 2010 Sep;30(9):1825-31.

http://dx.doi.org/10.1161/ATVBAHA.109.200303 PMid:20448211 